\title{
¿Diferencias encubiertas entre grupos? Efecto del método analítico sobre las conclusiones
}

\author{
Hidden differences between groups? Effect of analytical \\ method on the conclusions.
}

Sr. Editor:

El marco teórico de referencia es importante debido a que orienta las hipótesis de estudio con base en la evidencia existente $y$, posteriormente, los resultados obtenidos pueden darle soporte, o no. Sin embargo, el marco analítico empleado, que en última instancia dará validez a los hallazgos, debe estar en coherencia con el diseño, lo que incluye el tamaño muestral y tipo de muestreo utilizado.

No es nuevo para el lector que la prueba de significancia de hipótesis nula (PSHN; asociada al $p$-valor) es criticada ${ }^{1}$ debido a algunas limitaciones inherentes al método, como la sensibilidad al tamaño muestral (n), entre otras. Brevemente, aún con los mismos indicadores descriptivos (p.e., medias y desviaciones estándar), la hipótesis nula puede retenerse con $n$ pequeño, y no retenerse con $n$ grande. Esto implica una desventaja en estudios donde, sea por características propias de la muestra o por un diseño establecido, $n$ sea pequeño (p.e., $n<30$ ). Para casos como estos, las medidas de magnitud del efecto (ME) brindan información más realista sobre asociación, diferencia o influencia analizada.
En el estudio de Pérez-Pichardo y colaboradores ${ }^{2}$ fueron comparados dos grupos de niños, con TEA y desarrollo neurotípico, respecto a medidas directas e indirectas de las funciones ejecutivas, concluyendo que existen diferencias solo en las medidas indirectas, mientras que en las directas, el desempeño es similar entre los grupos. Sin duda, lo primero que se destaca es que, con siete personas por grupo, el uso de la PSHN es cuestionable debido a lo mencionado líneas arriba. Un estudio al que hacen referencia, ${ }^{3}$ complementa la PSHN con una medida de ME, la $r$, utilizada para dar una medida de asociación entre grupo y puntuación, lo que pudo ser aplicado en el manuscrito aludido. ${ }^{2}$

Entonces, en vista que no se cuenta con la información suficiente calcular la $r$, fue obtenida la $d$ de Cohen usando los datos de la media y desviación estándar de los cuadros 3 y $4,{ }^{4}$ obteniendo resultados que difieren de lo reportado respecto a la medida directa (Cuadro $\mathbf{1}$ ).

En síntesis, la medición indirecta presenta diferencias marcadas según criterios clásicos $(d>$ $.80)^{5}$ como más recientes $(d>1.15)^{6}$ entre los dos grupos, y a diferencia de lo mencionado 
Cuadro 1. Reevaluación de las diferencias entre grupos

\begin{tabular}{|c|c|c|c|}
\hline BRIEF & $d$ & EFEN & $d$ \\
\hline Inhibición & 2.16 & $\begin{array}{l}\text { Fluidez } \\
\text { fonológica }\end{array}$ & -0.88 \\
\hline Flexibilidad & 1.73 & $\begin{array}{l}\text { Fluidez } \\
\text { semántica }\end{array}$ & -0.88 \\
\hline Control emocional & 1.54 & Sendero gris & -1.25 \\
\hline BRI & 1.95 & $\begin{array}{l}\text { Sendero } \\
\text { a color }\end{array}$ & -1.06 \\
\hline Iniciación & 1.45 & Anillas & 0.69 \\
\hline Memoria de trabajo & 1.84 & Interferencia & -0.74 \\
\hline Planeación & 1.97 & & \\
\hline $\begin{array}{l}\text { Organización de } \\
\text { materiales }\end{array}$ & 1.09 & & \\
\hline Monitoreo & 1.63 & & \\
\hline MI & 1.94 & & \\
\hline GEC & 2.11 & & \\
\hline
\end{tabular}

en el manuscrito ("Ios niños con TEA obtienen puntuaciones en las medidas directas similares a los niños con desarrollo neurotípico"; p. 19), también la medición directa, que muestran diferencias no despreciables $(d>.80)$ a favor de los niños con desarrollo neurotípico (excepto en la tarea Anillas).

Concluyendo, es necesario aunar los hallazgos basados en la PSHN con la ME a fin de proporcionar un panorama completo al usuario del conocimiento, para que se pueda contrastar y valorar la información brindada a la luz del diseño empleado. Asimismo, dada la complejidad del tema abordado y las implicancias prácticas de los resultados, es recomendable, tal como lo indican los autores, ampliar la muestra para consolidar los resultados así como analizar y reportar las propiedades psicométricas de los instrumentos, toda vez que si no se cuenta con esta evidencia, peligra la validez de las inferencias $y$, en consecuencia, la validez del estudio.

\section{REFERENCIAS}

1. Fritz CO, Morris PE, Richler JJ. Effect size estimates: Current use, calculations, and interpretation. J Exp Psychol Gen. 2012; 141: 2-18.

2. Pérez-Pichardo MF, Ruz-Sahrur A, Barrera-Morales K, MooEstrella J. Medidas directas e indirectas de las funciones ejecutivas en niños con trastorno de espectro autista. Acta Pediatr Mex. 2018; 39(1):13-22.

3. Gómez-Pérez MM, Calero MD, Mata S, Molinero C. Discrepancies between direct and indirect measures of interpersonal and neurocognitive skills in autism spectrum disorder children. J Clin Exp Neuropsychol. 2016;38(8):1-12.

4. Dominguez-Lara S. Magnitud del efecto, una guía rápida. Educ Med 2016. Manuscrito en prensa.

5. Cohen J. A power primer. Psychol Bull. 1992; 112: 155-9.

6. Ferguson CJ. An effect size primer: A guide for clinicians and researchers. Prof Psychol Res Pract. 2009; 40: 532-8.

Sergio Dominguez-Lara Instituto de Investigación de Psicología Universidad de San Martín de Porres Lima, Perú. Av. Tomás Marsano 242 (5to piso), Lima 34 - Perú sdominguezmpcs@gmail.com sdominguezl@usmp.pe 